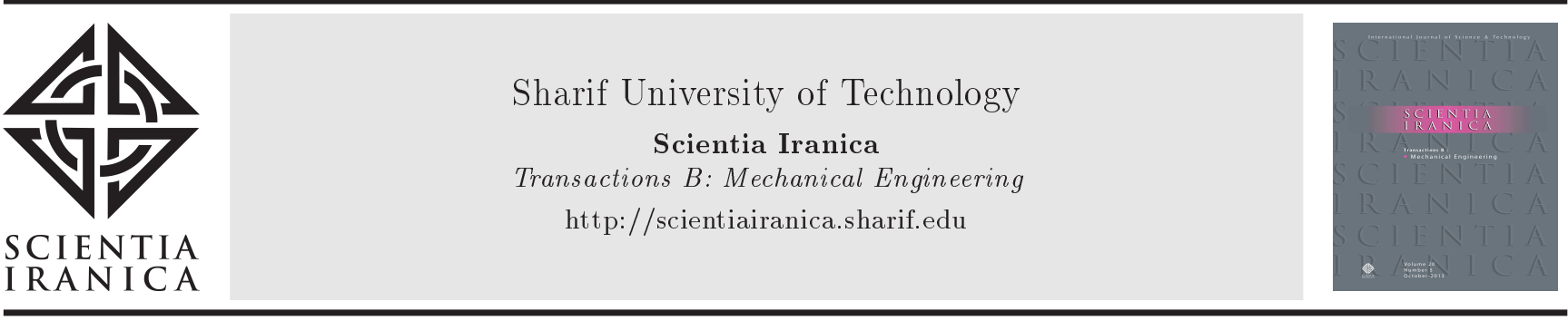

\title{
Optimal control of hybrid electric vehicles by considering engine and tire/road noises
}

\author{
M. Delkhosh ${ }^{\mathrm{a}}$, M. Aliramezani ${ }^{\mathrm{b}}$, M. Irannejad ${ }^{\mathrm{a}}$, and N. Lashgarian Azad ${ }^{\mathrm{c}, *}$ \\ a. School of Mechanical Engineering, Sharif University of Technology, Tehran, P.O. Box 11155-9567, Iran. \\ b. Department of Mechanical Engineering, University of Alberta, Edmonton, Postal Code T6G 2R3, Canada. \\ c. School of System Design Engineering, University of Waterloo, Waterloo, Ontario, Canada.
}

Received 29 May 2020; received in revised form 17 January 2021; accepted 17 May 2021

\author{
KEYWORDS \\ Hybrid electric \\ vehicle; \\ Noise emission; \\ Equivalent \\ consumption \\ minimization strategy; \\ Fuel consumption; \\ Engine noise; \\ Tire/road noise.
}

\begin{abstract}
Along with exhaust emissions and Fuel Consumptions (FCs), noise emission from cars is one of the main concerns of automotive industry. Hybridization is a promising method to not only make automobiles more environmentally-friendly, but also reduce their noise emissions. However, a proper control design for Hybrid Electric Vehicles (HEVs) to make noise emissions lower is still required in addition to exhaust emissions and FC reductions. In this study, we modify Equivalent Consumption Minimization Strategy (ECMS) to keep the engine noise less than tire/road noise during driving. A test bench is established for calculating the engine noise and brake specific FC. Moreover, tire/road noise is experimentally defined as a function of the vehicle speed. It is shown that by implementing the basic ECMS, the engine noise exceeds the tire/road noise in some moments of driving cycle, which is annoying to the passengers. Therefore, a modified ECMS is proposed to limit the candidate engine operating points such that the engine noise does not exceed the tire/road noise. It is shown that the engine noise level is kept below the tire/road noise level by using the modified ECMS at the expense of a very small increase (about 1\%) in the vehicle's FC.
\end{abstract}

(C) 2021 Sharif University of Technology. All rights reserved.

\section{Introduction}

Reducing Fuel Consumption (FC), exhaust emissions, and noise emission has always been the main objective of the automotive industry [1-4]. Different diseases are the result of people's exposure to high noise levels [5]. Therefore, reducing noise emissions is of high importance for car manufacturers [6].

The development of Hybrid Electric Vehicles (HEVs) potentially offers an opportunity to reduce the

*. Corresponding author. Tel.: +1 519-888-4567 E-mail addresses: m_delkhosh@mech.sharif.edu ( $M$. Delkhosh); aliramez@ualberta.ca (M. Aliramezani); irannejad_mostafa@mech.sharif.ir (M. Irannejad); nlashgarianazad@uwaterloo.ca (N. Lashgarian Azad)

doi: $10.24200 /$ sci. 2021.56065 .4535 noise emitted from vehicles. In addition to reducing the vehicle noise, HEVs play a key role in reducing exhaust emissions and FCs. The noise/exhaust emissions and FC are reduced by employing an electric motor as the auxiliary power source and, also, applying flexible energy management strategies to manage power distributions between the engine and the electric motor $[7,8]$.

The most important noise sources of HEVs are combustion noise, engine intake and exhaust systems, engine start/stops, electric motor/generator, as well as tire/road [9]. Among these noise sources, the main ones are the tire/road and engine [9-11]. As described in different studies $[9,10,12]$, the electric motor noise is very lower than the engine and tire/road noise. In fact, some studies $[9,13]$ have attempted to evaluate the necessity of adding extra artificial noise in the electric mode to be acoustically perceived by the pedestrians. 
As one of the main noise sources, the engine noise level should be measured employing a reliable technique to control the engine efficiency and noise simultaneously. In-cylinder pressure trace analyses provide a reliable technique for the engine combustion noise assessment $[14,15]$.

In order to evaluate the tire/road noise, it is necessary to have reliable acoustical measurements. There are several methods for tire/pavement noise measurements. The measurement method directly depends on the application [16].

The noise emissions of HEVs and Electric Vehicles (EVs) have been of interest recently. Calvo et al. [17] and Jabben et al. [18] evaluated the noise emission of passenger cars in urban transportations in Europe and studied the effect of driving cycles on the emitted noise. Govindswamy et al. [19] and Komada and Yoshioka [20] evaluated the noise reduction methods for the main noise sources of an HEV containing the motor noise, engine startups, and engine running noise. Guo et al. [21] studied range-extended EVs to evaluate their Noise, Vibration, and Harshness (NVH) sources including interior noise level, accelerations of the auxiliary power source stands, and the seat track. Pallas et al. [22] proposed a noise emission model for light conventional vehicles and EVs on several road surfaces. Franck et al. [23] investigated required steps for the acoustic simulation of electric machines to evaluate their noise level. Gasparoni et al. [24] examined the noise output of different types of tires currently used for a number of EVs and concluded that there was a linear relation between the logarithmic vehicle speed and overall maximum pass-by in $\mathrm{dB}$. Klerk and Ossipov [25] employed Operational Transfer Path Analysis (OTPA) method to analyze the tire noise. Also, Berckmans et al. [26] used the substitution monopole technique to establish a prediction model for calculating the tire noise.

As discussed before, the energy management strategy strongly impacts the emitted noise of HEVs. The proper design of the energy management strategy leads to the operation of the engine in low noise emission regions. Among different HEV energy management strategies, the Equivalent Consumption Minimization Strategy (ECMS) is one of the most popular ones. ECMS is categorized as a local optimization strategy, in which instantaneous optimization of a predefined cost function is accomplished at each moment of the driving. Accordingly, ECMS can be employed as a real-time control strategy which offers a sub-optimal power distribution between the engine and the electric motor.

The studies on HEV energy management strategies have been mainly focused on optimizing the strategies for fuel economy [27-31]. To date, little attention has been paid to modifications of HEV energy manage- ment strategies to reduce the engine emitted noises. Millo et al. [32] established an energy management strategy to reduce the engine noise of a range-extended EV. Also, Delkhosh et al. [33] modified a rule-based energy management strategy [34] to take the engine noise under the noise level of tire/road with the aim of improving the ride comfort. Due to high importance of the mentioned concern, more researches should be implemented to optimize HEV control strategies to reduce noise emissions of their engines.

This paper aims to investigate the effects of considering the engine noise in the ECMS strategy design for an HEV, which is done for the first time to the best knowledge of the authors. To do so, at the first stage, an experimental model for the engine is established to obtain the engine noise and FC data. Also, a test bench to determine the tire/road noise as a function of the vehicle speed is developed. After introducing the ECMS method and describing its shortcoming in terms of NVH criteria, a variation of the basic ECMS is suggested to take the engine noise below the tire/road noise level during the vehicle operations. Finally, the effectiveness of the proposed countermeasure is investigated through a comparison of the modified ECMS with the basic ECMS.

\section{Method}

In this section, first, the test benches to compute the engine and tire noises are explained. Then, the ECMS strategy is described. The modified version of ECMS strategy (considering NVH constraints) is proposed. Finally, the proposed strategy is compared with the standard one.

\subsection{Engine noise}

As mentioned before, two major noise sources of HEVs are the engine and tire/road. In order to incorporate these noise sources into the energy management strategy, it is necessary to calculate the noise emitted by these sources.

The combustion process is the main noise source of the engine which generally increases the noise level as the engine load and speed increase [35].

An experimental setup including the engine test bench and the related components is shown in Figure 1. A Horiba WT 190 dynamometer, AVL PLU $116 \mathrm{H}$ flow meter, and $A V L 619$ Indimeter are used for assessing the engine torque, fuel, rate and in-cylinder pressure trace, respectively. A four-cylinder 1.5L gasoline engine has been launched on the test stand presented in Figure 1.

The test results are used to calculate bsfc and noise map of the engine coupled to a passive dynamometer. It should be noted that the noise map is achieved through employing a modified algorithm 


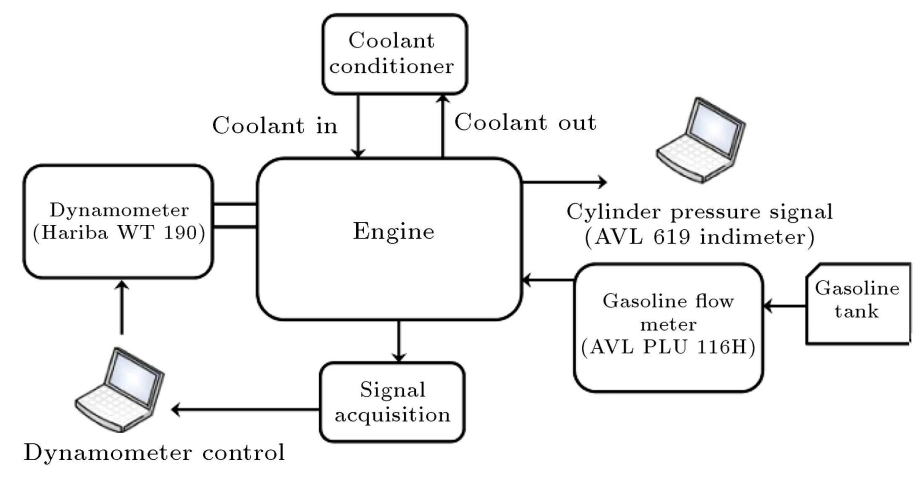

(a)

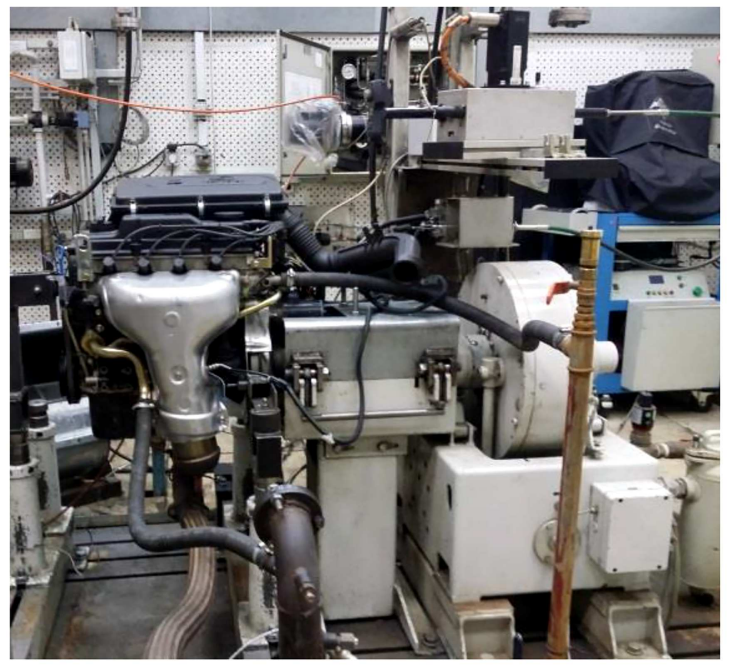

(b)

Figure 1. (a) Schematic view of used experimental setup. (b) Actual experimental setup.

originally developed by Shahlari et al. [36] based on incylinder pressure trace. The noise (in $\mathrm{dB}$ ) is calculated using:

$$
\text { Noise }=20 \log _{10}\left(\frac{P_{R M S}}{20 \mu P a}\right),
$$

where $P_{R M S}$ means the root mean square of the filtered pressure. In this equation, is normalized by $20 \mu \mathrm{Pa}$ which is the human hearing threshold.

The bsfc and noise data obtained from the experimental model are presented in Figures $2 \mathrm{a}$ and $2 \mathrm{~b}$, respectively. Figure 2 a reveals that the bsfc-optimal line of the engine can be drawn. Using this line, for a known value of the engine power, the engine speed for which the bsfc is minimal can be determined. Figure $2 b$ shows that the more the engine power and speed is, the greater the engine noise will be.

\subsection{Tire/road noise}

As discussed before, besides the engine, another important noise source of a vehicle is the tire. This noise is the outcome of interaction between the road surface

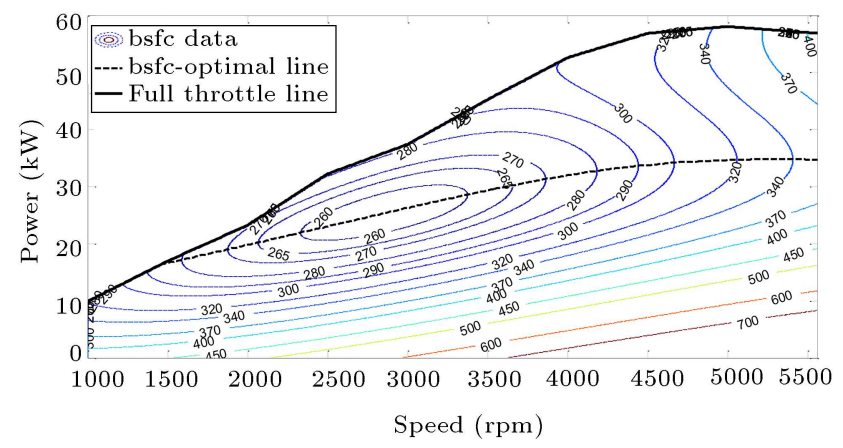

Figure 2a. bsfc (brake specific fuel consumption) map of the baseline engine (in $\mathrm{gr} / \mathrm{kWh}$ ).

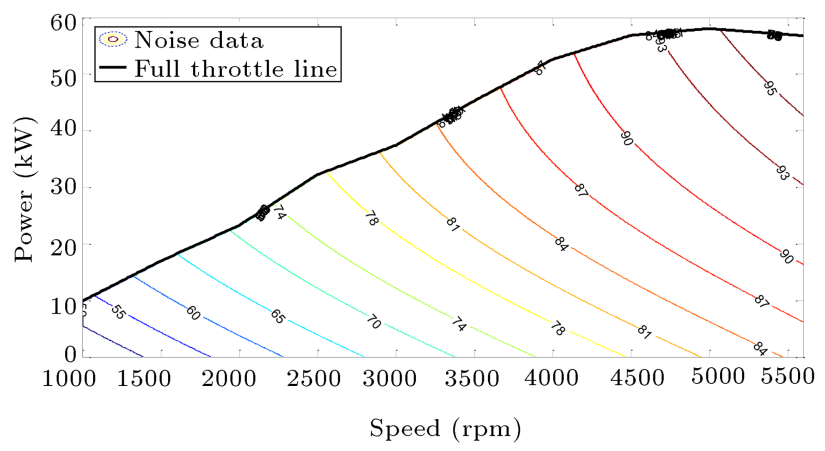

Figure 2b. Noise map of the baseline engine (in dB).

and the tire [37]. Different methods of measuring the tire/road noise are available and can be classified from different viewpoints. In the standardization process, there are four main methods: Coast-By (CB) method, Close-Proximity (CPX) method (previously called the Trailer method), Laboratory Drum (LD) method, and Trailer Coast-By (TCB) method [38]. In the present work, LD method is selected to measure the tire/road noise and fulfill the requirements of the proposed energy management strategy. LD method is selected because of its controllability and its lower background noise.

In the present work, two tires (C1-type as specified by the supplier) were chosen to be installed on the vehicle and their rolling noise was measured by different microphones. The tire noise measurements were carried out in the anechoic room of Saipa Automobile Research and Innovation Center. The cutoff frequency of this anechoic room is $63 \mathrm{~Hz}$, namely the sound waves above this frequency are not reflected from the room walls. A single-axle drum is installed inside the room which rotates the wheels (when the engine is turned off and the transmission is disengaged); 
therefore, the rolling sound of the tire can be measured by microphones.

The employed drum is a low noise Schenck drum (equipped with a surface that resembles an actual road). A multichannel data acquisition system (Difatype Scadas II), a microphone pre-amplifier (Brüel \& Kjaer-type 2671), a sound level calibrator (Brüel \& Kjaer-type 4231), and a microphone (Brüel \& Kjaertype 4188) are used for data collection. All of these devices are calibrated according to the corresponding standards.

Eleven microphones are located at different positions around the vehicle, near the tires, and inside the vehicle. The positions of the microphones are shown schematically in Figure 3a.

The test is repeated at different speeds (i.e., 60, $70,75,80,85,90$, and $100 \mathrm{~km} / \mathrm{h}$ ), each one for 3 seconds. At each speed, the tire noise is measured three times and averaged. For example, the noise measured by the microphones at $90 \mathrm{~km} / \mathrm{h}$ is presented in Figure 3b.

As discussed in different previous studies like $[9,10,22]$, the tire noise (including aerodynamic noise) mainly depends on the vehicle speed and it can be

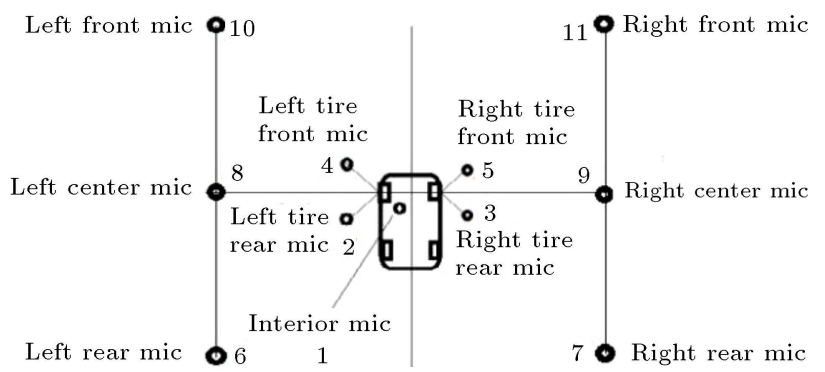

Figure 3a. Location of microphones in the test stand.

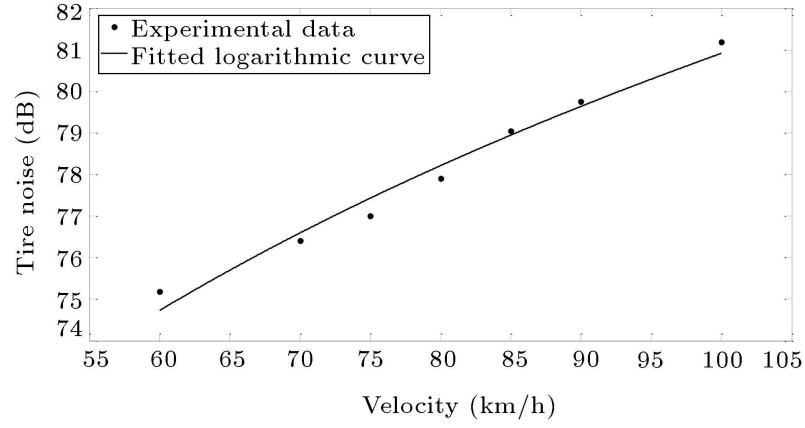

Figure 4. Variation of the tire/road noise measured by the interior microphone with respect to the vehicle speed.

defined as a logarithmic function of the speed $(V)$, as shown in Eq. (2):

$$
L_{\text {Tire }}=A+B \log (V),
$$

where $A$ and $B$ are two constants which are determined based on some experiments. The values of $A$ and $B$ for the tire noise measured by the inside microphone are 25.13 and 27.89 , respectively. The measured noise by the inside microphone and the fitted logarithmic curve are presented in Figure 4.

\subsection{Equivalent Consumption Minimization Strategy (ECMS)}

As mentioned previously, ECMS is categorized as an instantaneous optimization control strategy. In this strategy, the objective is to minimize the overall FC calculated by converting the electric energy consumption to an equivalent FC. The objective function in this strategy can be defined as follows [39]:

$$
J(t, u)=\Delta E_{I C E}(t, u)+s(t) \Delta E_{E M}(t, u),
$$

where $\Delta E_{E M}$ and $\Delta E_{I C E}$ are the electrical and fuel energy usages at the considered time interval,

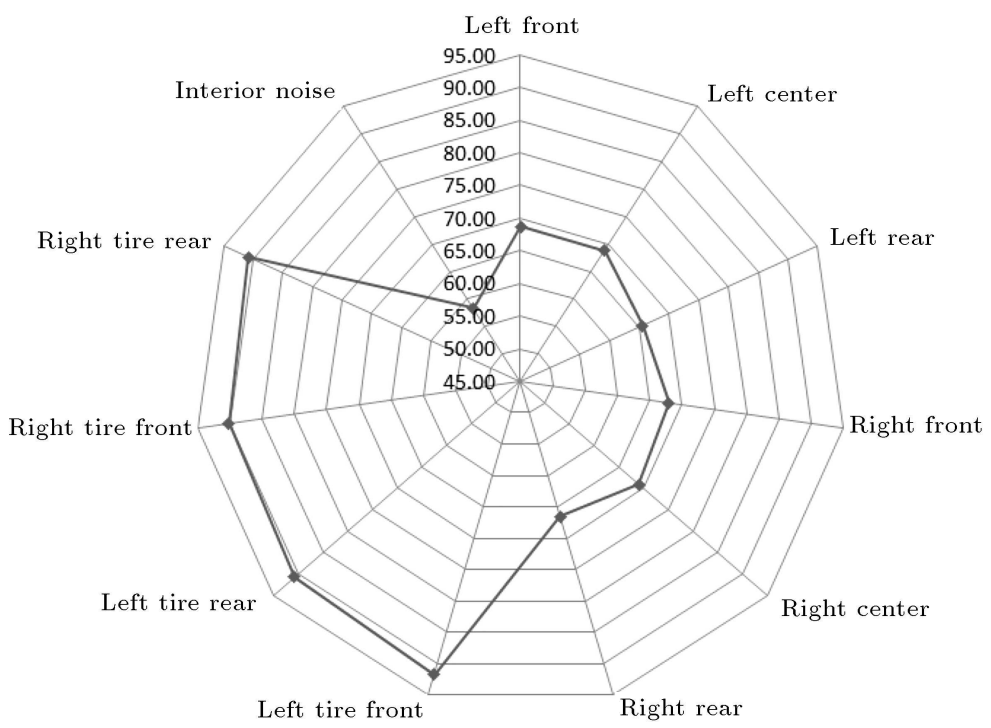

Figure 3b. Noise measured by the microphones at $90 \mathrm{~km} / \mathrm{h}$. 
respectively. $s(t)$ is a conversion factor defined in the following part and $u(t)$ is the control parameter of the ECMS approach which is defined as the percentage of the total required power supplied by the EM $\left(P_{E M} / P_{\text {req }}\right)$. Using this parameter, the power values that should be provided by the ICE and EM are determined; therefore, the energy consumption of these power sources can be determined. Consequently, the objective function value for the considered $u(t)$ can be calculated. According to the above definition, if $u(t)=0$, all of the required power will be provided by the ICE (pure thermal mode), while $u(t)=1$ means that the EM will be the only power source to propel the vehicle (pure electric mode). Furthermore, if $u(t)<0$, the ICE should provide power that is greater than the required amount and the extra power will be stored in the battery (charge mode) and also, $0<u(t)<1$ means that the both ICE and EM will propel the vehicle (discharge mode).

As stated before, $s(t)$ is the conversion factor whose value denotes the impact of electric energy consumption on the overall FC. There are different studies that have proposed some methods for defining this factor [39-42]. The method employed in this work is the one presented by Sciarretta et al. [39]. In this approach, the vehicle is considered in some predefined driving cycles and then, the parameters that affect the conversion factor are defined. These parameters are the charge $\left(s_{c h g}\right)$ and discharge $\left(s_{d i s}\right)$ equivalence factors which are determined at the end of the driving cycle. In the above-mentioned reference, it has been demonstrated that the values of each parameter for different driving cycles are approximately the same, and also, the average of each parameter over the considered driving cycles can be used in determining the conversion factor. After determining these equivalence factors, a probability function $(p(t))$ is defined to calculate the conversion factor at each moment of the driving cycle. This function defines the probability of obtaining a positive electrical energy at the driving cycle end point. Using the defined parameters, the conversion factor is defined as:

$$
s(t)=p(t) s_{d i s}+(1-p(t)) s_{c h g} \text {. }
$$

In order to find an optimal operating point at each moment of the driving, the control parameter $u(t)$ changes from its lower limit $\left(-u_{l}\right)$ to its upper limit $\left(u_{r}\right)$, and then the value for which the cost function $(J(t, u))$ is minimal will be selected as the optimum control parameter $\left(u_{\text {opt }}(t)\right)$. Consequently, at each moment of the driving, the optimal power split between the vehicle's power sources can be determined.

The studied vehicle in this study is a mid-sized parallel HEV equipped with Continuously Variable Transmission (CVT). The vehicle configuration is displayed in Figure 5.

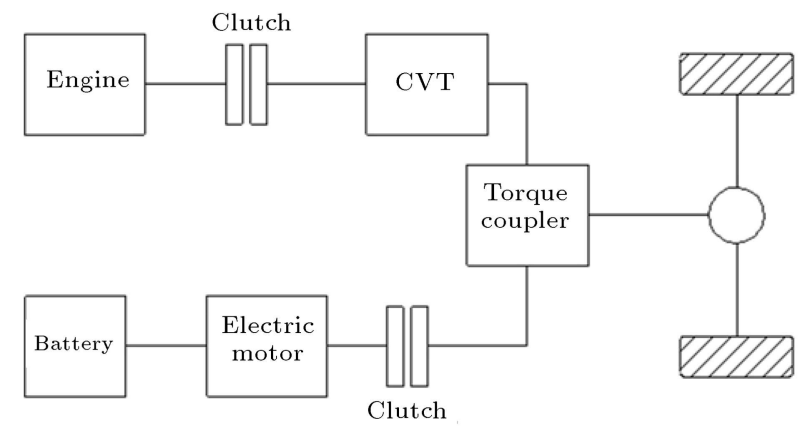

Figure 5. Configuration of the studied Hybrid Electric Vehicle (HEV).

The components of this vehicle are listed in Table 1.

The HEV simulation model used in this study was presented previously by Delkhosh et al. [34]. In that paper, the simulation models of all of the major components as well as experimental data of the engine's FC, the efficiency of electric motor and battery have been provided. As demonstrated in that study, the model validation is confirmed upon comparing simulation results of the model with the given experimental data.

As an example of the ECMS performance in a driving cycle, the ECMS is executed for the abovementioned HEV model in Urban Dynamometer Driving Schedule (UDDS) and the results are presented in Figure 6a.

In this figure, each point denotes an operation point in the considered driving cycle. The optimal mode (i.e., pure electric mode, discharge mode, charge mode, and pure thermal mode) for each point is shown in this figure. As illustrated, the points of optimal modes create some distinct optimal regions. At low speeds and powers, the optimal mode is pure electric mode. In these points, the engine will be shut off and the motor propels the vehicle. The reason is that at these points, the engine is not sufficiently efficient (see Figure 2a), and also, the electric motor can provide all of the required power. At low speeds and high powers, neither the engine nor the electric motor

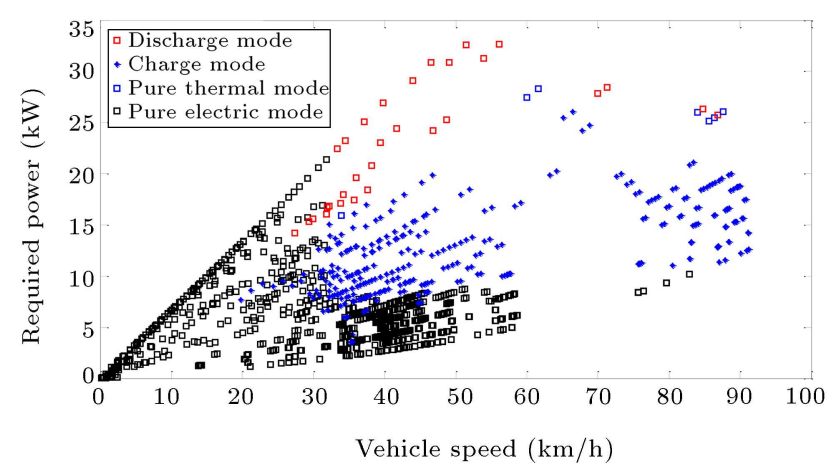

Figure 6a. Optimal modes of Hybrid Electric Vehicle (HEV) in Urban Dynamometer Driving Schedule (UDDS). 
Table 1. Characteristics of the Hybrid Electric Vehicle (HEV) components.

\begin{tabular}{|c|c|}
\hline Component & Features \\
\hline Vehicle [43] & Light passenger car \\
\hline Frontal area & $2.09 \mathrm{~m}^{2}$ \\
\hline Rolling resistance & 0.013 \\
\hline Drag coefficient & 0.36 \\
\hline Wheel radius & $0.279 \mathrm{~m}$ \\
\hline Total mass & $1100 \mathrm{~kg}$ \\
\hline \multicolumn{2}{|l|}{ Engine [43] } \\
\hline Volume & $1.5 \mathrm{~L}$ \\
\hline Maximum power & $58.1 \mathrm{~kW}$ at $5000 \mathrm{rpm}$ \\
\hline Peak efficiency & 0.34 \\
\hline Battery [44] & Lithium-ion polymer rechargeable \\
\hline Number of modules & 96 \\
\hline Nominal capacity & $10.05 \mathrm{Ah}$ \\
\hline Nominal voltage & $14.8 \mathrm{~V}$ \\
\hline Internal impedance & $15 \mathrm{~m} \Omega$ \\
\hline Maximum allowable current & $10.05 \mathrm{~A}$ (charge), $120 \mathrm{~A}$ (discharge) \\
\hline Electric motor [45] & Asynchronous induction motor/generator \\
\hline Maximum power & $30 \mathrm{~kW}$ \\
\hline Maximum torque & $300 \mathrm{Nm}$ \\
\hline Peak efficiency & 0.9 \\
\hline Power train $[46]$ & Continuously variable transmission \\
\hline efficiency & variable with respect to input torque, speed and speed ratio \\
\hline Differential speed ratio and efficiency & $3.895,97 \%$ \\
\hline
\end{tabular}

alone can provide the required power, or these power sources at these points are not efficient. Hence, both of them together provide the required power (discharge mode). At high power and speed points, the engine supplies power greater than the required value and the additional power is used to charge the battery (charge mode). The reason is that the engine tends to operate in the bsfc-optimal points (shown in Figure 2a) and it, therefore, operates with power greater than the required power to reach the bsfc-optimal points, as shown in Figure 6b. This figure reveals that a large number of operation points lie near the bsfc-optimal line. It is notable that the results of ECMS application for other driving cycles are similar to the UDDS case.

It should be noted that on the left edge of the scattered points in Figure 6a, the required power is proportional to speed. In other words, at these points, the required traction forces (at the wheel) are almost equal. The reason is that at these points, the vehicle accelerations are the same with and equal to the

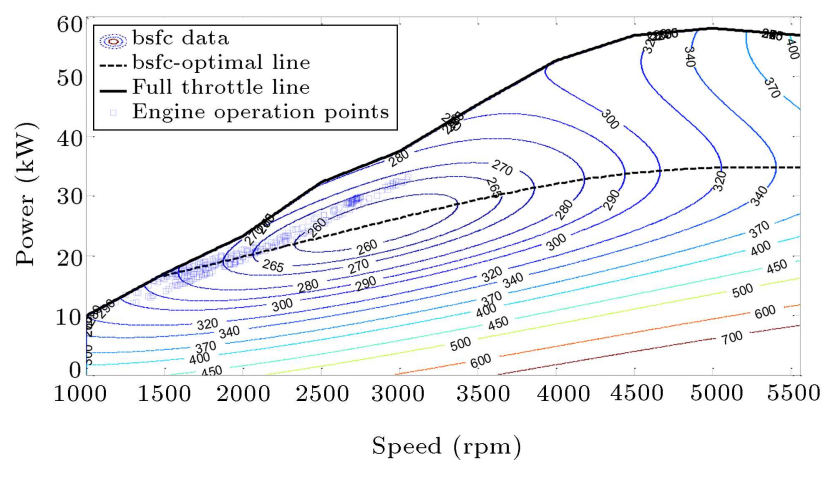

Figure 6 b. Operation points of the engine while using the basic Equivalent Consumption Minimization Strategy (ECMS) in Urban Dynamometer Driving Schedule (UDDS).

maximum acceleration in the UDDS $\left(1.4752 \mathrm{~m} / \mathrm{s}^{2}\right)$. At low speeds, the values of aerodynamics resistance force and rolling resistance force are negligible compared to the acceleration resistance force. Therefore, at the 


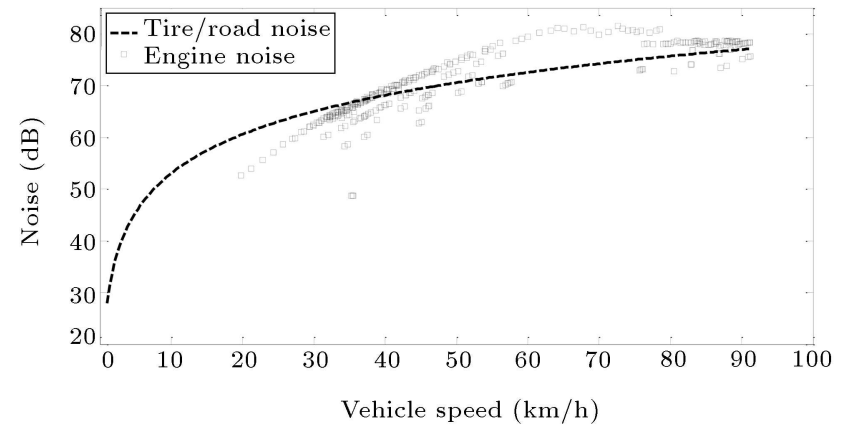

Figure 7. Tire/road noise and engine noise in Urban Dynamometer Driving Schedule (UDDS).

maximum acceleration points (when the vehicle speed is low), the acceleration resistance force dominates other forces and thus, the vehicle traction forces will be almost the same (around $2.2 \mathrm{kN}$ ).

Obviously, in the basic version of the ECMS, no attention has been devoted to the engine noise. Therefore, the engine noise may exceed the tire/road noise which will degrade the ride comfort. This fact is shown in Figure 7. In this figure, the noise of the engine and the tire/road in the UDDS cycle are shown. As shown, the noise of the engine exceeds the tire/road noise at some moments of the driving. In order to address this issue, a modification to the basic ECMS will be proposed in the following section.

\subsection{ECMS with NVH constraints}

In order to address the discussed issue, NVH constraints are incorporated into the ECMS and their impacts are evaluated. In order to take the noise of the engine and the tire/road into account, the following procedure is proposed.

At each instant of the driving, the road noise is computed according to the vehicle speed and Eq. (2). As discussed, each value of the control parameter $u$ (which is within the range $\left[-u_{l}, u_{r}\right]$ ) determines the power distribution between the power sources, and the engine power is calculated by:

$$
P_{I C E}(t, u)=(1-u(t)) P_{r e q}(t) \text {. }
$$

Once the engine power is defined, its rotational speed is determined regarding the bsfc-optimal line (presented in Figure 2a) and the speed ratio range of the CVT. After defining the operation point of the engine, the engine noise at this point (according to Figure 2b) is compared to the tire/road noise (shown in Figure 4). If the engine noise is more than the road noise, the corresponding control parameter $u$ is eliminated and the controller examines another value in the predefined range. The flowchart of this algorithm is presented in Figure 8.

As can be seen, the input of the controller is the speed profile and the output is the optimal power distribution between the engine and the electric motor.
It should be noted that it may be impossible to run the engine at the bsfc-optimal points at some moments of the driving. According to the flowchart, the rotational speed of the engine is determined in the corresponding block. After defining the engine speed, the speed ratio of CVT required to reach this rpm is defined. If the required speed ratio is in the CVT speed ratio range, the engine can operate in the optimal rpm. Otherwise, the CVT will create the nearest speed ratio to the desired value and the engine speed is defined according to this speed ratio and the vehicle speed. Consequently, in cases that the desired speed ratio cannot be generated by the CVT, the engine cannot operate at the bsfc-optimal point.

With use of this method, the engine noise is kept below the tire noise. This fact is highlighted in Figure 9. It can be inferred from the figure that the engine acoustic emissions lie within the boundaries defined by the tire/road noise. As a result, through the application of the modified ECMS, the engine noise is totally masked by the tire noise and, therefore, leads to a remarkable improvement in the comfort of the HEV.

The optimal modes of the HEV in the UDDS while applying the modified ECMS are shown in Figure 10. By comparing this figure with Figure 6(a), through the application of the modifications, some of the 'charge mode' points change into 'discharge mode'. Also, some of the 'charge mode' points change into the 'pure engine mode'. This happens since at these points, the engine noise exceeds the road noise (while using the basic ECMS) and the modified ECMS forces the engine to operate at low power values. It should be noted that 'pure electric mode' points do not change to the other modes by applying modifications.

The operation points of the engine through the application of the modified ECMS in UDDS are shown in Figure 11. A comparison between this figure and Figure $6 \mathrm{~b}$ reveals that the engine tends to operate at lower speeds, at which the engine noise is smaller (see Figure 7). In case of using the basic ECMS, the engine speed is up to $3100 \mathrm{rpm}$, while the maximum speed of the engine for the modified ECMS case is $2600 \mathrm{rpm}$. It is worth mentioning that similar results for other driving cycles are observed.

The variation of the battery state of charge during UDDS while using the modified ECMS is shown in Figure 12. As can be seen, the sustainability of the state of charge is guaranteed by using the modified ECMS.

\subsection{Comparison of modified ECMS and basic ECMS}

One of the major concerns about the modification of $\mathrm{HEV}$ control strategies is the impact of the modification on the vehicle's FC. Hence, the modified ECMS should be compared to the basic strategy in terms of 


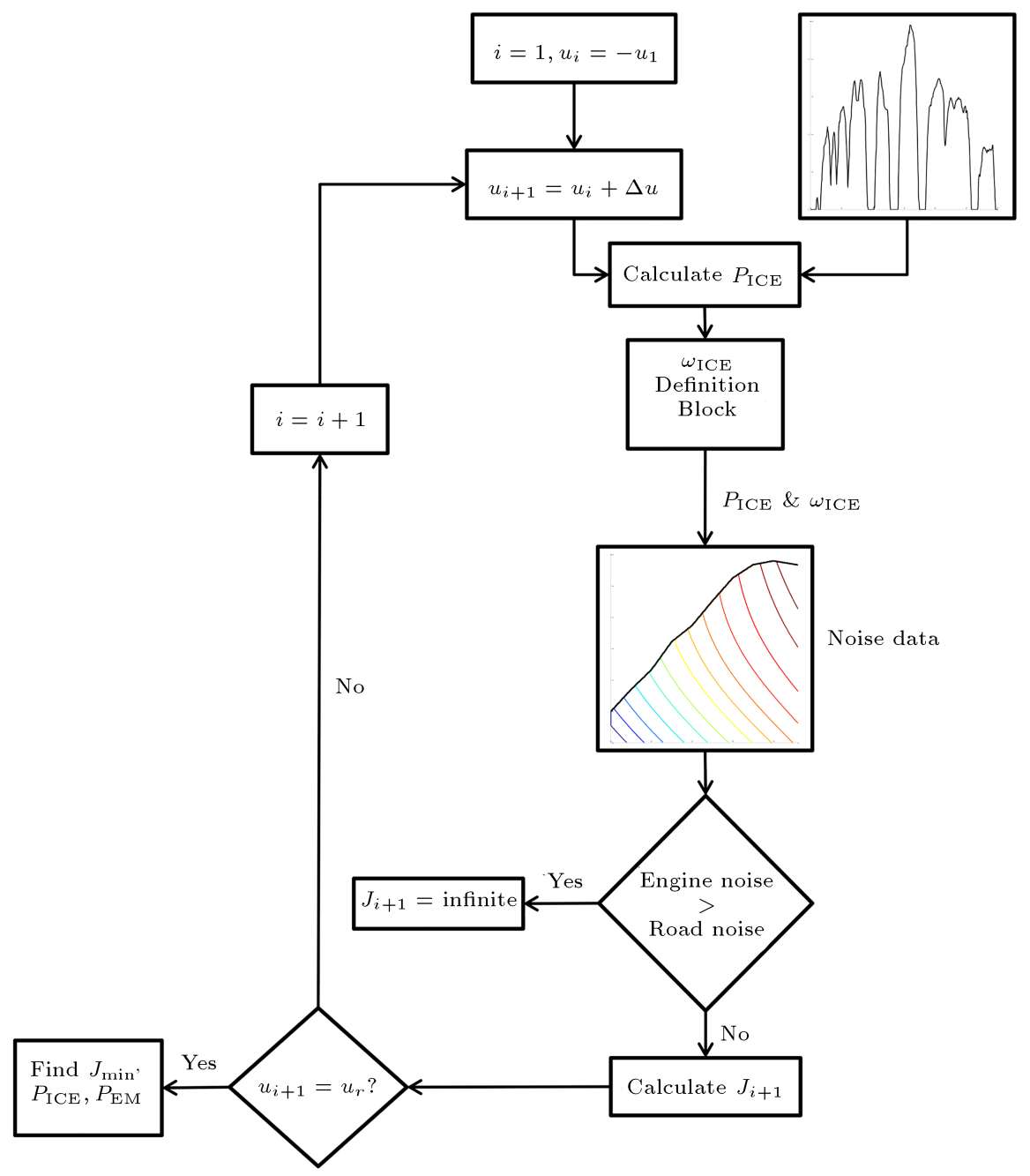

Figure 8. Flowchart of the modified Equivalent Consumption Minimization Strategy (ECMS).

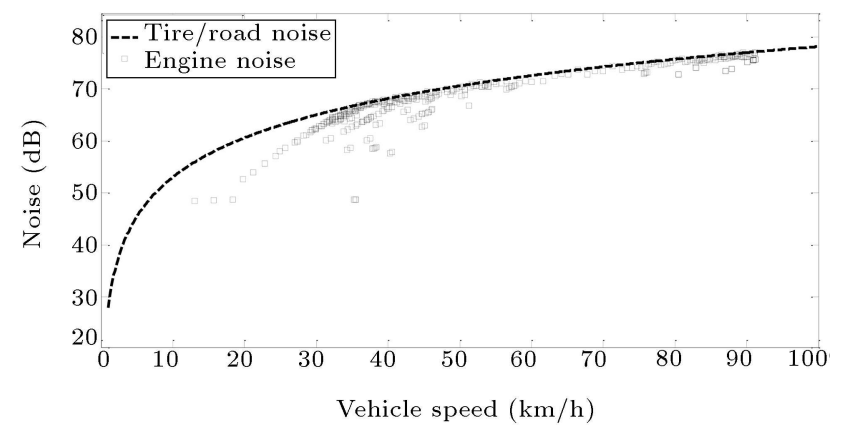

Figure 9. Tire noise and engine noise in Urban Dynamometer Driving Schedule (UDDS) while applying the modified Equivalent Consumption Minimization Strategy (ECMS).

FC to ensure that the fuel economy is not sacrificed in exchange for the benefits of the ride comfort. This comparison is carried out in various driving cycles and the results are presented in Table 2 .

It should be noted that in the HEV, both of the ICE and the electric motor consume energy. Therefore,

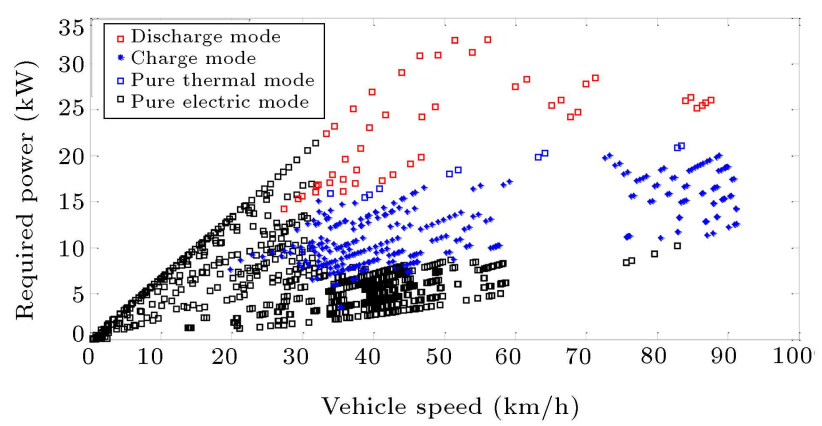

Figure 10. Optimal modes of Hybrid Electric Vehicle (HEV) in Urban Dynamometer Driving Schedule (UDDS) while applying modified Equivalent Consumption Minimization Strategy (ECMS).

a comparison of the FC may not be suitable as it neglects the energy consumption related to the battery. A possible solution to take both of the energy consumers into consideration is to use the equivalent $\mathrm{FC}(J)$ as the comparison function. As discussed in the ECMS description, this function converts the electric energy 
Table 2. Function $J(\mathrm{~kJ})$ in the case of using the basic Equivalent Consumption Minimization Strategy (ECMS) and modified ECMS during different driving cycles.

\begin{tabular}{cccccc}
\hline & UDDS & SC03 & NEDC & Japan 1015 & FTP \\
\hline Basic ECMS & 13.866 & 7.041 & 16.028 & 8.187 & 2.127 \\
Modified ECMS & 13.962 & 7.099 & 16.145 & 8.214 & 2.136 \\
Difference percent & $0.69 \%$ & $0.82 \%$ & $0.73 \%$ & $0.33 \%$ & $0.42 \%$ \\
\hline
\end{tabular}

Note: UDDS: Urban Dynamometer Driving Schedule; NEDC: New European Driving Cycle;

FTP: Federal Test Procedure

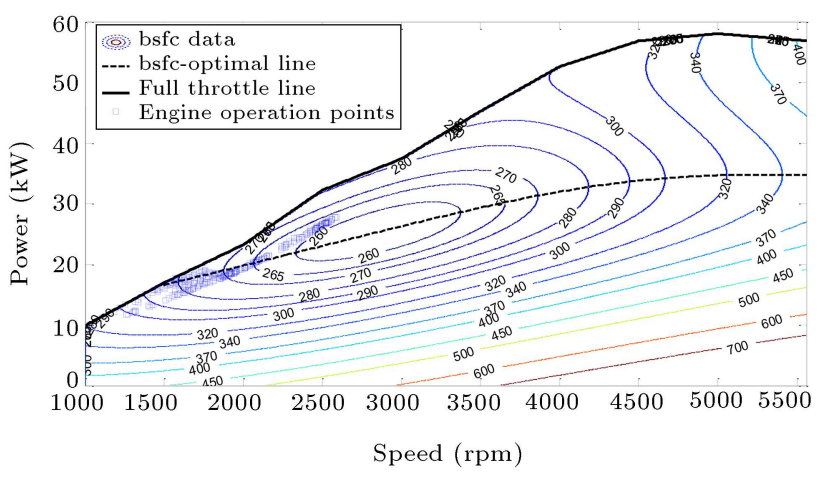

Figure 11. Operation points of the engine while using the modified Equivalent Consumption Minimization Strategy (ECMS) in Urban Dynamometer Driving Schedule (UDDS).

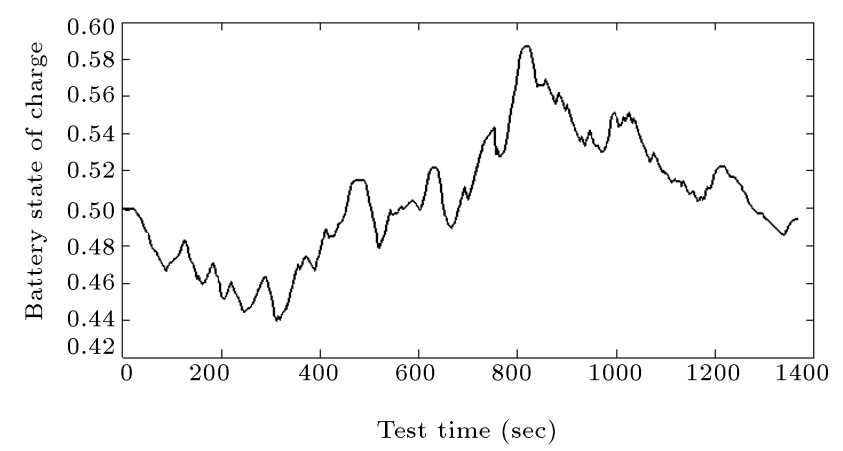

Figure 12. Variation of the battery state of charge during Urban Dynamometer Driving Schedule (UDDS) while using the modified Equivalent Consumption Minimization Strategy (ECMS).

usage to an equivalent $\mathrm{FC}$ and calculates the overall FC (see Eq. (3)). Hence, this function is considered as the comparison function.

The comparison should be ideally made over the whole life cycle of the vehicle. However, this is not practical and is usually performed over a short trip such as common driving cycles. In the present study, the considered cycles are UDDS, SC03, New European Driving Cycle (NEDC), Japan 1015 and Federal Test Procedure (FTP).

The comparison shown in this table reveals that the modified ECMS causes more energy consumptions than the basic ECMS. However, the percentage of the difference is not more than $1 \%$. In fact, the introduction of the NVH constraints into the ECMS does not remarkably move the center of gravity of the energy distribution to the low efficiency area (as demonstrated by Figure 11). Consequently, the proposed modification can be considered useful in terms of the engine noise while the energy consumption growth by applying the proposed modification is not remarkable.

\section{Conclusion}

This work introduced a promising method to improve the energy management strategy of Hybrid Electric Vehicles (HEVs) by taking into account Nuise, Vibration and Harshness (NVH) issues related to engine operations. The process of defining the engine working point in the basic Equivalent Consumption Minimization Strategy (ECMS) was changed to maintain the emitted engine noise below the tire/road noise level. At the beginning, the use of a test bench constructed to calculate the noise and bsfc of the engine was presented. The tire/road noise was also determined using another test bench developed for this purpose. Afterwards, the basic ECMS strategy was introduced which forced the engine to operate around the bsfc-optimal points. As presented, through the application of the basic ECMS, the engine noise exceeded the tire/road noise at some moments of the driving cycle and therefore, degraded the ride comfort. Therefore, the NVH requirements were addressed through a modification of the basic ECMS. The result of the modification was to keep the engine noise under the road noise and also operate the engine at lower speeds. Finally, concerning the vehicle's Fuel Consumption (FC), it was shown that the vehicle's FC through the application of the modified ECMS in several driving cycles was more than that of the basic ECMS, but the FC growth was less than $1 \%$. Therefore, the proposed modification for incorporating the NVH constraints into the ECMS does not lead to significant worsening of the vehicle fuel efficiency in comparison to the basic ECMS, which is desirable.

As a future study, the start/stop noise of engine can be considered in calculating the engine noise and also, a proper energy management strategy can be developed to take the engine noise for this case below the tire/road noise level. 


\section{Acknowledgment}

This research was supported by Barez Industrial Group, which is a major and experienced tire manufacturing factory located in Kerman, Iran. We thank our colleagues from Barez Industrial Group, especially Mr. Mohsen Ghaffari, director of research and development department of Barez Industrial Group, who generously provided us with tire/road noise data. Also, the authors are grateful to MEGA MOTOR Company for supporting the engine experiments.

\section{Nomenclature}

CVT Continuously Variable Transmission

ECMS Equivalent Consumption Minimization Strategy

EV Electric Vehicle

FC Fuel Consumption

FTP Federal Test Procedure

HEV Hybrid Electric Vehicle

NEDC New European Driving Cycle

NVH Noise, Vibration and Harshness

OTPA Operational Transfer Path Analysis

UDDS Urban Dynamometer Driving Schedule

$J \quad$ Cost function

$L_{\text {Tire }} \quad$ Tire sound level

$p$

Probability function

$P_{I C E} \quad$ Engine power

$P_{r e q} \quad$ Vehicle required power

$P_{R M S} \quad$ Root mean square of the filtered pressure

$P_{E M} \quad$ Electric motor power

$S \quad$ Conversion factor

$S_{c h g} \quad$ Charge equivalence factor

$S_{\text {dis }} \quad$ Discharge equivalence factor

$u \quad$ Control parameter

$V \quad$ Vehicle speed

$\Delta E_{I C E} \quad$ Fuel energy usages

$\Delta E_{E M} \quad$ Electrical energy usages

\section{References}

1. Taghavipour, A., Vajedi, M., and Azad N.L., Intelligent Control of Connected Plug-in Hybrid Electric Vehicles, pp. 1-198, Springer International Publishing, Switzerland (2019).

2. Kumar, V., Rana, K.P.S., and Mishra, P. "Robust speed control of hybrid electric vehicle using fractional order fuzzy PD and PI controllers in cascade control loop", J Franklin Inst, 353(8), pp. 1713-1741 (2016).
3. Xu, D., Zhang, J., Zhou, B., et al. "Robust hierarchical estimator of clutch torques for a compound powersplit hybrid electric vehicle", MSSP, 134(1), pp. 1-17 (2019).

4. Ağbulut, Ü., Sarıdemir, S., and Karagöz, M. "Experimental investigation of fuel oil (isoamyl alcohol) and diesel blends in a CI engine", Fuel, 267(1), pp. 1-8 (2020).

5. Huang, H.B., Huang, X.R., Yang, M.L., et al. "Identification of vehicle interior noise sources based on wavelet transform and partial coherence analysis", MSSP, 109(1), pp. 247-267 (2018).

6. Qin, Y., Tang, Xi., Jia, T., et al. "Noise and vibration suppression in hybrid electric vehicles: State of the art and challenges", Renew. Sustain. Energy Rev, 124(1), pp. 1-16 (2020).

7. Peng, J., He, H., and Xiong, R. "Rule based energy management strategy for a series-parallel plug-in hybrid electric bus optimized by dynamic programming", Appl. Energy, 185(2), pp. 1633-1643 (2017).

8. Sabri, M., Danapalasingam, K.A., and Rahmat, M.F. "A review on hybrid electric vehicles architecture and energy management strategies", Renew. Sustain. Energy Rev, 53(1), pp. 1433-1442 (2016).

9. Braun, M.E., Walsh, S.J., Horner, J.L., et al. "Noise source characteristics in the ISO 362 vehicle pass-by noise test: Literature review", Appl. Acoust., 74(11), pp. 1241-1265 (2013).

10. Guo, R., Cao, C., Mi, Y., et al. "Experimental investigation of the noise, vibration and harshness performances of a range-extended electric vehicle", $P$ I Mech Eng. D-J Aut., 230(5), pp. 650-663 (2015).

11. Sarıdemir, S. and Ağbulut, Ü. "Combustion, performance, vibration and noise characteristics of cottonseed methyl ester-diesel blends fuelled engine", Biofuels, 1(10), pp. 1-10 (2019).

12. Mosquera-Sánchez, J.A., Sarrazin, M., Janssens, K., et al. "Multiple target sound quality balance for hybrid electric powertrain noise", MSSP, 99(1), pp. 478-503 (2018).

13. Sandberg, U., Goubert, L., and Mioduszewski, P. "Are vehicles driven in electric mode so quiet that they need acoustic warning signals", 20th Int. Cong. on Acoustics, Sydney, Australia, pp. 1-11 (2010).

14. Dernotte, J., Dec, J., and Ji, C. "Investigation of the sources of combustion noise in HCCI engines", $S A E$ Int. J. Engines, 7(2), pp. 730-761 (2014).

15. Bi, F., Li, L., Zhang, J., et al. "Source identification of gasoline engine noise based on continuous wavelet transform and EEMD-RobustICA", Appl. Acoust., 100(1), pp. 34-42 (2015).

16. Donavan, P. and Rymer, B. "Assessment of highway pavements for tire/road noise generation", SAE Technical Paper 2003-01-1536 (2003). 
17. Calvo, J.A., Álvarez-Caldas, C., San Román, J.L., et al. "Influence of vehicle driving parameters on the noise caused by passenger cars in urban traffic", Transport Res D-TR E, 17(7), pp. 509-513 (2012).

18. Jabben, J., Verheijen, E., and Potma, C. "Noise reduction by electric vehicles in the Netherlands", Proc. of Internoise, New York, USA, pp. 1-8 (2012).

19. Govindswamy, K., Wellmann, T., and Eisele, G. "Aspects of NVH integration in hybrid vehicles", $S A E$ Int. J. Passeng. Cars Mech. Syst., 2(1), pp. 1396-1405 (2009).

20. Komada, M. and Yoshioka, T. "Noise and vibration reduction technology in new generation hybrid vehicle development", SAE Technical Paper, 114(6), pp. 2648-2655 (2005).

21. Guo, R., Mi, Y., and Cao, C. "Subjective and objective evaluation of APU start-stop NVH for a rangeextended electric vehicle", SAE Technical Paper 201501-0047 (2015).

22. Pallas, M.A., Bérengier, M., Chatagnon, R., et al. "Towards a model for electric vehicle noise emission in the European prediction method CNOSSOS-EU", Appl. Acoust., 113(1), pp. 89-101 (2016).

23. Franck, D., van der Giet, M., and Hameyer, K. "Towards low audible noise drives for FEV applications", 14th Int. EPE/PEMC, Aachen, Germany, pp. 25-30 (2010).

24. Gasparoni, S., Czuka, M., Wehr, R., et al. "Impact of low-noise tyres on electric vehicle noise emission", IFSTTAR, Norway, pp. 1-53 (2015).

25. de Klerk, D. and Ossipov, A. "Operational transfer path analysis: Theory, guidelines and tire noise application", MSSP, 24(7), pp. 1950-1962 (2010).

26. Berckmans, D., Kindt, P., Sas, P., et al. "Evaluation of substitution monopole models for tire noise sound synthesis", MSSP, 24(1), pp. 240-255 (2010).

27. Hou, C., Xu, L., Wang, H., et al. "Energy management of plug-in hybrid electric vehicles with unknown trip length", J Franklin Inst, 352(2), pp. 500-518 (2015).

28. Montazeri-Gh, M., Poursamad, A., and Ghalichi, B. "Application of genetic algorithm for optimization of control strategy in parallel hybrid electric vehicles", $J$ Franklin Inst, 343(4), pp. 420-435 (2006).

29. Delkhosh, M., Saadat Foumani, M., and Falahati, F. "A modified control strategy for parallel hybrid electric vehicles equipped with continuously variable transmission", Sci. Iran., 23(3), pp. 966-975 (2016).

30. Delkhosh, M., Saadat Foumani, M., and Rostami, P. "Optimization of powertrain and control strategy of hybrid electric vehicle", Sci. Iran., 22(5), pp. 18421854 (2015).

31. Solouk, A., Shakiba-herfeh, M., Kannan, K., et al. "Fuel economy benefits of integrating a multi-mode
Low Temperature Combustion (LTC) engine in a series extended range electric powertrain", SAE Technical Paper 2016-10-17 (2016).

32. Millo, F., Rolando, L., Mallamo, F., et al. "Development of an optimal strategy for the energy management of a range-extended electric vehicle with additional noise, vibration and harshness constraints", P I Mech. Eng. D-J Aut., 227(1), pp. 4-16 (2013).

33. Delkhosh, M., Aliramezani, M., and Khadem Nahvi, M. "Investigating the effect of engine noise on power management strategy of a hybrid electric vehicle", $P I$ Mech. Eng. D-J Aut., 232(10), pp. 1287-1296 (2017).

34. Delkhosh, M., Saadat Foumani, M., Azad, N.L., et al. "A new control strategy for hybrid electric vehicles equipped with continuously variable transmission", $P$ I MECH ENG D-J AUT, 230(6), pp. 803-816 (2015).

35. Uludamar, E., Tosun, E., and Aydın, K. "Experimental and regression analysis of noise and vibration of a compression ignition engine fuelled with various biodiesels", Fuel, 177(1), pp. 326-333 (2016).

36. Shahlari, A.J., Hocking, C., Kurtz, E., et al. "Comparison of compression ignition engine noise metrics in low-temperature combustion regimes", SAE Int. J. Engines, 6(1), pp. 541-552 (2013).

37. Sandberg, U. "Tyre/road noise: myths and realities", Int. Cong. Exhib. Noise Control Eng., Hauge, Netherland, pp. 1-24 (2001).

38. Sandberg, U. and Ejsmont, J.A., Tyre/Road Noise Reference Book, pp. 1-640, Informex Press, Kisa, Sweden (2002).

39. Sciarretta, A., Back, M., and Guzzella, L. "Optimal control of parallel hybrid electric vehicles", IEEE T Contr Syst T, 12(3), pp. 352-363 (2004).

40. Park, J. and Park, J.H. "Development of equivalent fuel consumption minimization strategy for hybrid electric vehicles", Int. J. Automot. Technol., 13(5), pp. 835-843 (2012).

41. García, P., Torreglosa, J.P., Fernández, L.M., et al. "Viability study of a FC-battery-SC tramway controlled by equivalent consumption minimization strategy", Int. J. Hydrog. Energy, 37(11), pp. 9368-9382 (2012).

42. Zhang, C. and Vahid, A. "Real-time optimal control of plug-in hybrid vehicles with trip preview", American Control Conference (ACC), pp. 6917-6922 (2010).

43. Saipa Corporation [Online]. Available: http://www. saipacorp.com/portal/Home/

44. Gita Battery [Online]. Available: http://www. gitabattery.com/

45. "ADVISOR library reorganized structure" http://advvehiclesim.sourceforge.net/LibReorg.html (2003). 
46. Delkhosh, M. and Saadat Foumani, M. "Multiobjective geometrical optimization of full toroidal CVT", Int. J. Automot. Technol., 14(5), pp. 707-715 (2013).

\section{Biographies}

Mojtaba Delkhosh received his BSc, MSc, and PhD degrees in Mechanical Engineering from Sharif University of Technology, Tehran, Iran in 2009, 2011, and 2016, respectively. Also, he undertook his postdoctoral studies in this university in the field of hybrid electric vehicle. Currently, he is an adjunct Professor at Sharif University of Technology and Henan University. His primary research interests lie in vehicle dynamics, design of hybrid vehicles, machine design, vibration analysis, power transmission systems, and optimization algorithms. Also, he has accomplished more than 70 industrial projects as the project manager. These projects are in the field of machine design, automation, vibration analysis, and proactive maintenance.

Masoud Aliramezani received the BS degree in Mechanical Engineering from K. N. Toosi University of Technology, Tehran, Iran in 2010, the MS degree in Mechanical Engineering from Sharif University of Technology, Tehran, Iran in 2012, and the PhD degree in the same field of study from the University of Alberta (UofA), Edmonton, Canada in 2019. He has been working on modeling and control of Internal Combustion Engines (ICEs) for more than 10 years both in the automotive industry and in academia. His research has been focused on developing physics-based and machine-learning based models for internal combustion engines, after treatment systems and emission sensors. He was with Iran Khodro Powertrain Co (IPCO) from 2009 to 2010 and from 2012 to 2014 working on engine calibration and emission reduction of light-duty spark ignition and diesel engines, as well as energy management of hybrid electric vehicles. He was a graduate research and teaching assistant from 2014 to 2019 working on advanced ICE modeling and control strategies focusing on electrochemical sensors for realtime emission measurement and feedback control of
ICE gaseous emissions. He is now working on advanced machine learning techniques to model and control ICEs and electrochemical gas sensors.

Mostafa Irannejad is a Mechanical and Biomedical Engineering Researcher. He completed his BSc of Applied Mechanics degree at Amirkabir University of Technology (Tehran Polytechnic), where he graduated among the top three students of his class. He then received his MCs degree from Amirkabir University of Technology, under the supervision of Dr. Ohadi. He continued his education as a PhD student in Mechanical Engineering at Sharif University of Technology. He received his $\mathrm{PhD}$ degree under the supervision of Dr. Ahmadian and Dr. Mohammadi in 2021. Dr. Irrannejad has taught over 20 academic courses in mechanical engineering (including statics, dynamics, dynamics of machinery, mechanical vibrations, automatic control, and strength of materials) as a teacher assistant at both Amirkabir and Sharif Universities. In addition to teaching and his academic research, Dr. Irrannejad has contributed to seven industrial R\&D projects as a research fellow and has presented various workshops on acoustics, noise, and vibrations. His research interests include dynamics (rotor-dynamics in particular), vibration, automatic control, noise and acoustics, biomechanical engineering, condition monitoring, and fault diagnosis.

Nasser Lashgarian Azad is currently an Associate Professor at the Department of Systems Design Engineering, University of Waterloo, and the Director of Smart Hybrid and Electric Vehicle Systems (SHEVS) Laboratory. He was a Postdoctoral Fellow with the Vehicle Dynamics and Control Laboratory, Department of Mechanical Engineering, University of California, Berkeley, CA, USA. His primary research interests lie in control of connected hybrid and electric vehicles, autonomous cars, and unmanned aerial vehicle quadrotors. He is also interested in applications of Artificial Intelligence to solving different engineering problems. Due to his outstanding work, he received an Early Researcher Award in 2015 from the Ministry of Research and Innovation, Ontario, Canada. 